Gynecologic and

Obstetric Investigation
Gynecol Obstet Invest 2019;84:583-590

DOI: $10.1159 / 000501034$
Received: January 25, 2019

Accepted after revision: May 19, 2019

Published online: June 18, 2019

\title{
Impact of Diabetes Mellitus on Postoperative Complications Following Laparoscopic Hysterectomy for Benign Indications
}

\author{
Kelly E. Corrigan ${ }^{a}$ Maria V. Vargas ${ }^{b}$ Hannah N. Robinson ${ }^{a}$ Alex Gu $^{a}$ \\ Chapman Wei $^{a}$ Paul Tyan ${ }^{c}$ Neha Singh ${ }^{d}$ Erryn E. Tappy ${ }^{\mathrm{e}}$ Gaby N. Moawad ${ }^{\mathrm{b}}$ \\ ${ }^{a}$ George Washington University School of Medicine and Health Sciences, Washington, DC, USA; ${ }^{b}$ Department of \\ Obstetrics and Gynecology, George Washington University School of Medicine and Health Sciences, Minimally \\ Invasive Gynecologic Surgery, Washington, DC, USA; ' $D$ Department of Obstetrics and Gynecology, University of

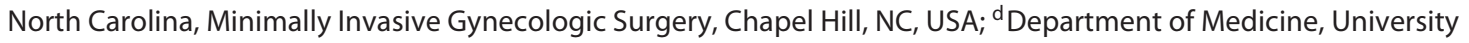 \\ at Buffalo School of Medicine, Buffalo, NY, USA; ' Department of Obstetrics and Gynecology, George Washington \\ University, Washington, DC, USA
}

\section{Keywords}

Hysterectomy · Laparoscopy · Diabetes mellitus ·

Postoperative complications · Laparoscopic surgery

\begin{abstract}
Background: Current research pertaining to minimally invasive gynecologic surgical outcomes in the context of diabetes mellitus (DM) is limited. This study seeks to evaluate the association between DM and postoperative complications following laparoscopic hysterectomy for benign indications. Methods: The American College of Surgeons National Surgical Quality Improvement Program database was utilized. We identified laparoscopic hysterectomies completed for benign indications from 2007 to 2016 using current procedural terminology codes. Complications were evaluated by DM status: non-insulin-dependent DM (NIDDM), insulindependent DM (IDDM), and non-DM. Postoperative complications were evaluated utilizing univariate and multivariate analyses. Results: We identified 56,640 laparoscopic hysterectomies. Though both the IDDM and NIDDM cohorts had an increased incidence of postoperative complications
\end{abstract}

\section{KARGER}

(c) 2019 S. Karger AG, Basel

E-Mail karger@karger.com

www.karger.com/goi compared to the non-diabetes cohort. The IDDM group had the highest incidence of all 3 cohorts. Compared to nonDM, the IDDM group had higher odds of reintubation (OR 4.23; 95\% Cl 1.59-11.19), urinary tract infection (OR 1.45; $95 \% \mathrm{Cl} 1.022-2.069)$, and extended length of stay (OR 1.75; 95\% CI 1.36-2.26). Conclusion: Both NIDDM and IDDM were independent risk factors for postoperative complications after laparoscopic hysterectomy. However, the IDDM cohort had the highest odds of complications. Diabetic patients should be carefully counseled regarding their elevated risk of perioperative complications.

๑) 2019 S. Karger AG, Basel

\section{Introduction}

Hysterectomy is the second most common surgical procedure performed on women, with $>450,000$ operations per year [1-3]. With advances in and increased

K.E.C. and M.V.V. contributed equally to this work.
Maria Victoria Vargas, MD

Department of Obstetrics and Gynecology, George Washington University School of Medicine and Health Sciences, Minimally Invasive Gynecologic Surgery 2150 Pennsylvania Avenue, Washington, DC 20037 (USA)

E-Mail mvvargas@mfa.gwu.edu 
Table 1. CPT codes utilized to identify laparoscopic hysterectomy cases

\begin{tabular}{ll}
\hline Code & Description \\
\hline 58541 & Laparoscopic supracervical hysterectomy $\leq 250 \mathrm{~g}$ \\
58542 & Laparoscopic supracervical hysterectomy $\leq 250 \mathrm{~g}$, with bilateral salpingo-oophorectomy \\
58543 & Laparoscopic supracervical hysterectomy $>250 \mathrm{~g}$ \\
58544 & Laparoscopic supracervical hysterectomy $>250 \mathrm{~g}$, with bilateral salpingo-oophorectomy \\
58550 & Laparoscopic-assisted vaginal hysterectomy $\leq 250 \mathrm{~g}$ \\
58552 & Laparoscopic-assisted vaginal hysterectomy $\leq 250 \mathrm{~g}$, with bilateral salpingo-oophorectomy \\
58553 & Laparoscopic-assisted vaginal hysterectomy $>250 \mathrm{~g}$ \\
58554 & Laparoscopic-assisted vaginal hysterectomy $>250 \mathrm{~g}$, with bilateral salpingo-oophorectomy \\
58570 & Total laparoscopic hysterectomy $\leq 250 \mathrm{~g}$ \\
58571 & Total laparoscopic hysterectomy $\leq 250 \mathrm{~g}$, with bilateral salpingo-oophorectomy \\
58572 & Total laparoscopic hysterectomy $>250 \mathrm{~g}$ \\
58573 & Total laparoscopic hysterectomy $>250 \mathrm{~g}$, with bilateral salpingo-oophorectomy \\
\hline
\end{tabular}

CPT, current procedural terminology.

availability of minimally invasive surgical techniques, a greater number of hysterectomies are being performed laparoscopically [1]. Laparoscopic hysterectomy has been associated with shorter hospital stays, faster recovery time, fewer infections, and less pain compared to the open approach [4].

Diabetes mellitus (DM) is becoming more prevalent on a global scale. By 2025, it is predicted that 700 million people will have DM [5]. DM has been associated with increased risk of adverse events during the postoperative period when compared to nondiabetic patients, including poor wound healing, respiratory infections, cardiac complications (myocardial infarction), intensive care unit admissions, and increased length of hospital stay [6-10].

The impact of DM on outcomes after laparoscopic hysterectomy, however, remains unreported. The purpose of this study was to identify patients who had undergone laparoscopic hysterectomy for benign indications using the American College of Surgeons National Surgical Quality Improvement Program (ACS-NSQIP) database and compare the incidence of early postoperative complications in patients with non-insulin-dependent DM (NIDDM), insulin-dependent DM (IDDM), and nondiabetic patients (non-DM).

\section{Methods}

Laparoscopic hysterectomies performed for benign indications between 2007 and 2016 were collected from the ACS-NSQIP database. Patients who underwent laparoscopic hysterectomy were identified using the current procedural terminology (CPT) codes reported in Table 1. Variables pertaining to demographics, preop- erative comorbidities, and perioperative complications (within 30 days of surgery) were evaluated. Exclusion criteria included (1) malignancy (2) concurrent procedures (3) missing body mass index (BMI), (4) missing age, and (5) missing DM status. Malignant cases were identified utilizing ICD 10 codes C51-C57 and ICD 9 codes 179,180 , and $182-184$ in the preoperative diagnosis, postoperative diagnosis, or both. If there was disagreement in regards to malignant status between the preoperative and postoperative diagnoses, the postoperative diagnosis was utilized for purposes of exclusion. Concurrent procedures were excluded by CPT codes not associated with laparoscopic hysterectomy (Table 1).

Demographic data collected included patient age, BMI, smoking status, preoperative dyspnea, preoperative functional status, and American Society of Anesthesiologists (ASA) class. Preoperative comorbidity data collected included DM status, bleeding disorder, congestive heart failure (CHF), chronic obstructive pulmonary disease (COPD), preoperative dialysis, disseminated cancer, hypertension (HTN)-requiring medication, preoperative weight loss, renal failure, chronic steroid use, and preoperative transfusion. Operative characteristics analyzed included length of operative time and specimen weight $<$ or $\geq 250$ g. Postoperative complications analyzed included wound infections (superficial surgical site, deep, organ/space), wound dehiscence, pneumonia, reintubation, failure to wean from ventilator within $48 \mathrm{~h}$, pulmonary embolism, renal insufficiency, renal failure, urinary tract infection, cardiac arrest, myocardial infarction, transfusion, deep venous thrombosis/thrombophlebitis, sepsis, septic shock, unplanned return to operating room, and extended length of stay (LOS; $\geq 3$ days).

Status of insulin dependence was used as a marker for disease severity in our analyses. Patients were divided into 3 cohorts based on their diabetes status, including (1) patients without DM (nonDM), (2) patients with NIDDM, and (3) patients with IDDM.

SPSS version 22 (Armonk, NY, USA) software was utilized for data analysis. Demographic characteristics, preoperative comorbidities, operative characteristics, and postoperative complications were analyzed using univariate analysis by Pearson's chisquare. For multivariate analysis to determine independent associations for postoperative complications, a Poisson logistic linear 
Fig. 1. Summary of laparoscopic hysterectomy cases from 2007 to 2016 ACS-NSQIP database included in data analysis. ACSNSQIP, American College of Surgeons National Surgical Quality Improvement Program; BMI, body mass index.

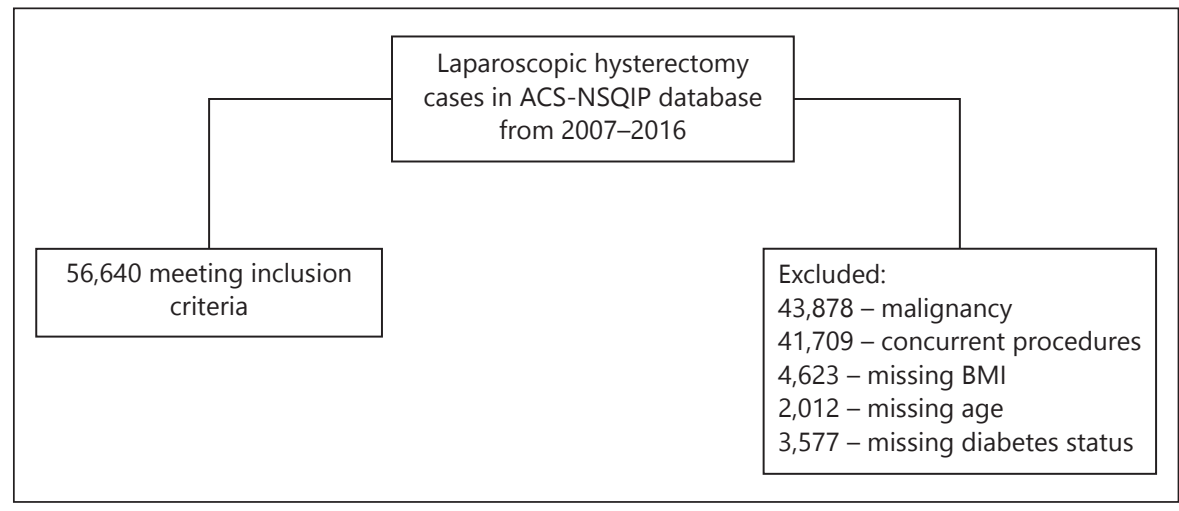

regression was performed. Results from the multivariate analysis are reports as ORs with a $95 \% \mathrm{CI}$. A $p$ value of $<0.05$ was used as a marker of significance.

\section{Results}

\section{Demographics and Preoperative Comorbidities}

A total of 56,640 cases met inclusion criteria (Fig. 1). The non-DM group was the largest, with 52,724 (93.1\%) cases. There were 2,806 (5.0\%) cases in the NIDDM group and $1,110(2.0 \%)$ cases in the IDDM group. Compared to the non-DM group, patients with NIDDM were more likely to be older $(p<0.001)$, have a higher BMI $(p<$ $0.001)$, be in a higher ASA class $(p<0.001)$, have dyspnea on exertion or at rest $(p<0.001)$, and have a lower preoperative functional status $(p<0.001)$. Patients in the NIDDM cohort were less likely to be smokers when compared to patients in the non-DM group $(p<0.001)$. $\mathrm{Pa}-$ tients with IDDM were more likely to be older $(p<0.001)$, have a higher BMI $(p<0.001)$, be in a higher ASA class $(p<0.001)$, have dyspnea on exertion or at rest $(p<0.001)$, and have a lower preoperative functional status $(p<$ 0.001 ) when compared to patients in the non-DM cohort. When comparing the NIDDM cohort to the IDDM cohort, the NIDDM cohort was more likely to have a higher BMI $(p=0.042)$. Patients in the IDDM cohort were more likely to have a higher ASA class $(p<0.001)$, be a smoker $(p<0.001)$, and have dyspnea on exertion or at rest $(p=0.001)$ when compared to the NIDDM cohort (Table 2).

The overall prevalence of preoperative comorbidities analyzed was low. HTN-requiring medication management was the most common preoperative comorbidity in the non-DM, NIDDM, and IDDM cohorts, occurring in $21.2,64.3$, and $69.7 \%$ of patients, respectively. Patients with NIDDM were more likely to have multiple preexisting medical conditions when compared to the non-DM group, including bleeding disorders $(p<0.001)$, COPD $(p<0.001)$, and HTN-requiring medication $(p<0.001)$. Furthermore, patients in the NIDDM cohort more likely to be on dialysis $(p=0.018)$ when compared to patients in the non-DM cohort. IDDM patients were more likely to have congestive heart failure (non-DM $p<0.001$; NIDDM $p<0.001$ ), COPD (non-DM $p<0.001$; NIDDM $p<$ 0.001 ), HTN-requiring medication (non-DM $p<0.001$; $\operatorname{NIDDM} p=0.001$ ), and renal failure (non-DM $p<0.001$; $\operatorname{NIDDM} p=0.001)$ when compared to both the non-DM and NIDDM groups. Patients with IDDM were also more likely to be on dialysis (non-DM $p<0.001$; NIDDM $p<$ 0.001) when compared to the non-DM and NIDDM groups. Patients in the IDDM cohort were more likely to be on steroids preoperatively $(p=0.011)$ when compared to the non-DM cohort and more likely to have preoperative weight loss $(p=0.038)$ when compared to the NIDDM cohort (Table 2).

\section{Operative Characteristics}

A majority of cases analyzed had a duration of $<240$ min. Among the non-DM cohort, 50,313 (95.4\%) cases had an operative duration of $<240 \mathrm{~min}$. Of the NIDDM and IDDM cohorts, 93.0 and $93.7 \%$ of cases, respectively, had an operative duration of $<240 \mathrm{~min}$. When compared to non-DM patients, however, NIDDM and IDDM patients were more likely to have an operative time of $>240$ $\min (\mathrm{NIDDM} p<0.001$; IDDM $p=0.006)$.

Additionally, a majority of patients had a hospital LOS $<3$ days. Of the non-DM cohort, 51,327 (97.4\%) had a hospital stay $<3$ days. In the NIDDM and IDDM cohorts, $2,715(96.8 \%)$ and $1,026(92.4 \%)$ cases, respectively, had a hospital stay of $<3$ days. NIDDM and IDDM patients were more likely to have a LOS $\geq 3$ days (NIDDM $p=$ 
Table 2. Demographics and Co-morbidities of 56,640 patients who underwent laparoscopic hysterectomy

\begin{tabular}{|c|c|c|c|c|c|c|c|c|c|}
\hline Overall & 52,724 & & 2,806 & & 1,110 & & & & \\
\hline \multicolumn{10}{|l|}{ Age, years } \\
\hline $18-30$ & 2,282 & 4.3 & 38 & 1.4 & 15 & 1.4 & $<0.001$ & $<0.001$ & 0.164 \\
\hline $51-60$ & 8,711 & 16.5 & 680 & 24.2 & 241 & 21.7 & & & \\
\hline$>60$ & 3,886 & 7.4 & 501 & 17.9 & 205 & 18.5 & & & \\
\hline \multicolumn{10}{|l|}{ BMI, kg/m² } \\
\hline$<18.5$ & 484 & 0.9 & 3 & 0.1 & 0 & 0.0 & $<0.001$ & $<0.001$ & 0.042 \\
\hline $18.5-24.9$ & 13,159 & 25.0 & 151 & 5.4 & 90 & 8.1 & & & \\
\hline $25-29.9$ & 150,002 & 28.5 & 437 & 15.6 & 165 & 14.9 & & & \\
\hline 1 or 2 & 44,029 & 83.5 & 1,290 & 46.0 & 306 & 27.6 & $<0.001$ & $<0.001$ & $<0.001$ \\
\hline 3 or 4 & 8,695 & 16.5 & 1,516 & 54.0 & 804 & 72.4 & & & \\
\hline \multicolumn{10}{|l|}{ Smoker } \\
\hline No & 42,220 & 80.1 & 2,367 & 84.4 & 873 & 78.6 & $<0.001$ & 0.238 & $<0.001$ \\
\hline Yes & 10,504 & 19.9 & 439 & 15.6 & 237 & 21.4 & & & \\
\hline \multicolumn{10}{|l|}{ Dyspnea } \\
\hline No dyspnea & 51,439 & 97.6 & 2,669 & 95.1 & 1,026 & 92.4 & $<0.001$ & $<0.001$ & 0.001 \\
\hline Moderate exertion & 1,249 & 2.4 & 135 & 4.8 & 80 & 7.2 & & & \\
\hline At rest & 36 & 0.1 & 2 & 0.1 & 4 & 0.4 & & & \\
\hline \multicolumn{10}{|l|}{ Functional status pre-op } \\
\hline Independent & 52,617 & 99.8 & 2,792 & 99.5 & 1,098 & 98.9 & $<0.001$ & $<0.001$ & 0.062 \\
\hline Partially dependent & 89 & 0.2 & 14 & 0.5 & 11 & 1.0 & & & \\
\hline Preoperative weight loss & 64 & 0.1 & 1 & 0.0 & 3 & 0.3 & 0.196 & 0.164 & 0.038 \\
\hline Renal failure & 4 & 0.0 & 0 & 0.0 & 4 & 0.4 & 0.645 & $<0.001$ & 0.001 \\
\hline Steroid use & 715 & 1.4 & 47 & 1.7 & 25 & 2.3 & 0.157 & 0.011 & 0.226 \\
\hline Transfusion & 172 & 0.3 & 11 & 0.4 & 3 & 0.3 & 0.554 & 0.746 & 0.565 \\
\hline
\end{tabular}

DM, diabetes mellitus; NIDDM, noninsulin-dependent diabetes mellitus; IDDM, insulin-dependent diabetes mellitus; BMI, body mass index; ASA class, American Society of Anesthesiologists class; CHF; congestive heart failure; COPD, chronic obstructive pulmonary disease; HTN, hypertension.

0.043; IDDM $p<0.001$ ) when compared to non-DM patients. IDDM patients were also more likely to have a longer hospital LOS when compared to NIDDM patients $(p<0.001)$. There was no statistically significant relationship in regards to uterine weight $\geq 250 \mathrm{~g}$ among the 3 cohorts (Table 3).

\section{Postoperative Complications}

Overall, the incidence of postoperative complications was low following laparoscopic hysterectomy, with a majority of complications occurring in $<3 \%$ of cases per cohort. Patients with NIDDM had higher incidence of superficial surgical site wound infection $(p=0.049)$ when compared to the non-DM cohort. In addition, both pa- 
Table 3. Operative characteristics of 56,640 patients who underwent laparoscopic hysterectomy

\begin{tabular}{|c|c|c|c|c|c|c|c|c|c|}
\hline & \multicolumn{2}{|c|}{ Non-DM } & \multicolumn{2}{|l|}{ NIDDM } & \multicolumn{2}{|l|}{ IDDM } & \multicolumn{3}{|l|}{$p$ value } \\
\hline \multicolumn{10}{|c|}{ Operative time, min } \\
\hline$<240$ & 50,313 & 95.4 & 2,610 & 93.0 & 1,040 & 93.7 & $<0.001$ & 0.006 & 0.447 \\
\hline$\geq 240$ & 2,411 & 4.6 & 196 & 7.0 & 70 & 6.3 & & & \\
\hline$\geq 250$ & 6,247 & 11.8 & 310 & 11.0 & 116 & 10.5 & & & \\
\hline \multicolumn{10}{|c|}{ Total LOS, days } \\
\hline$<3$ & 51,327 & 97.4 & 2,715 & 96.8 & 1,026 & 92.4 & 0.043 & $<0.001$ & $<0.001$ \\
\hline$\geq 3$ & 1,378 & 2.6 & 91 & 3.2 & 84 & 7.6 & & & \\
\hline
\end{tabular}

DM, diabetes mellitus; NIDDM, non-insulin-dependent diabetes mellitus; IDDM, insulin-dependent diabetes mellitus; LOS, length of stay.

Table 4. Postoperative complications and hospital LOS of 56,640 patients who underwent laparoscopic hysterectomy

\begin{tabular}{|c|c|c|c|c|c|c|c|c|c|}
\hline \multirow[t]{2}{*}{ Complications } & \multicolumn{2}{|l|}{ Non-DM } & \multicolumn{2}{|l|}{ NIDDM } & \multicolumn{2}{|l|}{ IDDM } & \multicolumn{3}{|l|}{$p$ value } \\
\hline & number & percentage & number & percentage & number & percentage & $\begin{array}{l}\text { NIDDM vs. } \\
\text { Non-DM }\end{array}$ & $\begin{array}{l}\text { IDDM vs. } \\
\text { Non-DM }\end{array}$ & $\begin{array}{l}\text { NIDDM vs. } \\
\text { IDDM }\end{array}$ \\
\hline Superficial surgical site wound infection & 436 & 0.8 & 33 & 1.2 & 15 & 1.4 & 0.049 & 0.058 & 0.653 \\
\hline Deep wound infection & 77 & 0.1 & 7 & 0.2 & 4 & 0.4 & 0.170 & 0.068 & 0.555 \\
\hline Organ/space infection & 460 & 0.9 & 32 & 1.1 & 7 & 0.6 & 0.140 & 0.390 & 0.148 \\
\hline Wound dehiscence & 113 & 0.2 & 7 & 0.2 & 2 & 0.2 & 0.696 & 0.807 & 0.683 \\
\hline Pneumonia & 54 & 0.1 & 0 & 0.0 & 4 & 0.4 & 0.090 & 0.010 & $<0.001$ \\
\hline Reintubation & 31 & 0.1 & 6 & 0.2 & 6 & 0.5 & 0.002 & $<0.001$ & 0.096 \\
\hline Pulmonary embolism & 93 & 0.2 & 4 & 0.1 & 0 & 0.0 & 0.676 & 0.161 & 0.208 \\
\hline Failure to wean & 12 & 0.0 & 4 & 0.1 & 2 & 0.2 & $<0.001$ & 0.001 & 0.786 \\
\hline Renal insufficiency & 17 & 0.0 & 1 & 0.0 & 2 & 0.2 & 0.922 & 0.009 & 0.141 \\
\hline Renal failure & 3 & 0.0 & 1 & 0.0 & 1 & 0.1 & 0.069 & 0.001 & 0.497 \\
\hline Urinary tract infections & 1,085 & 2.1 & 62 & 2.2 & 36 & 3.2 & 0.582 & 0.006 & 0.062 \\
\hline Cardiac arrest & 4 & 0.0 & 0 & 0.0 & 1 & 0.1 & 0.127 & 0.772 & 0.529 \\
\hline Myocardial infarction & 7 & 0.0 & 2 & 0.1 & 1 & 0.1 & 0.019 & 0.038 & 0.848 \\
\hline Transfusions & 531 & 1.0 & 34 & 1.2 & 20 & 1.8 & 0.293 & 0.009 & 0.154 \\
\hline Venous thromboembolic events & 44 & 0.1 & 4 & 0.1 & 1 & 0.1 & 0.299 & 0.940 & 0.679 \\
\hline Sepsis & 155 & 0.3 & 8 & 0.3 & 7 & 0.6 & 0.932 & 0.043 & 0.115 \\
\hline Septic shock & 18 & 0.0 & 3 & 0.1 & 1 & 0.1 & 0.053 & 0.326 & 0.882 \\
\hline Return to OR & 690 & 1.3 & 43 & 1.5 & 18 & 1.6 & 0.509 & 0.325 & 0.731 \\
\hline
\end{tabular}
stay.

DM, diabetes mellitus; NIDDM, non-insulin-dependent diabetes mellitus; IDDM, insulin-dependent diabetes mellitus; OR, operating room; LOS, length of

tients with NIDDM and IDDM had a higher incidence of reintubation (NIDDM $p=0.002$; IDDM $p<0.001$ ), failure to wean from the ventilator (NIDDM $p<0.001$; IDDM $p=0.001$ ), and myocardial infarction (NIDDM $p=0.019$; IDDM $p=0.038)$ when compared to the nonDM cohort. Patients with IDDM had a higher incidence of pneumonia $(p=0.010)$, renal insufficiency $(p=0.009)$, renal failure $(p=0.001)$, urinary tract infection $(p=$
$0.006)$, transfusion $(p=0.009)$, and sepsis $(p=0.043)$ when compared to non-DM patients. Patients in the IDDM cohort also had a higher incidence of postoperative pneumonia $(p<0.001)$ when compared to the NIDDM cohort (Table 4).

On multivariate analyses, NIDDM and IDDM were independent risk factors for several postoperative complications. NIDDM was found to be an independent risk 
Table 5. Multivariate analysis for if DM as independent risk factor for postoperative complications

\begin{tabular}{|c|c|c|c|c|}
\hline \multirow[t]{2}{*}{ Post-operative complication } & \multirow[t]{2}{*}{$p$ value } & \multirow[t]{2}{*}{ OR } & \multicolumn{2}{|c|}{$95 \% \mathrm{CI}$} \\
\hline & & & low & high \\
\hline \multicolumn{5}{|l|}{ NIDDM vs. Non-DM } \\
\hline Superficial surgical site wound infection & 0.576 & 1.113 & 0.764 & 1.621 \\
\hline Reintubation & 0.161 & 1.973 & 0.763 & 5.101 \\
\hline Failure to wean & 0.024 & 4.33 & 1.215 & 15.436 \\
\hline Myocardial infarction & 0.195 & 3.212 & 0.55 & 18.74 \\
\hline Extended LOS & 0.097 & 0.822 & 0.652 & 1.036 \\
\hline \multicolumn{5}{|l|}{ IDDM vs. Non-DM } \\
\hline Pneumonia & 0.348 & 1.689 & 0.565 & 5.049 \\
\hline Reintubation & 0.004 & 4.219 & 1.591 & 11.186 \\
\hline Failure to wean & 0.053 & 5.216 & 0.978 & 27.812 \\
\hline Renal insufficiency & 0.088 & 4.133 & 0.808 & 21.141 \\
\hline Renal failure & 0.966 & 0.002 & 0.000 & $6.74 \times 10^{\wedge} 121$ \\
\hline Urinary tract infection & 0.038 & 1.454 & 1.022 & 2.069 \\
\hline Myocardial infarction & 0.262 & 3.694 & 0.377 & 36.242 \\
\hline Transfusion & 0.180 & 1.389 & 0.859 & 2.245 \\
\hline Sepsis & 0.158 & 1.778 & 0.800 & 3.951 \\
\hline Extended LOS & $<0.001$ & 1.751 & 1.360 & 2.255 \\
\hline \multicolumn{5}{|l|}{ IDDM vs. NIDDM } \\
\hline Pneumonia & 0.983 & 0.000 & 0.000 & 0.000 \\
\hline Extended LOS & $<0.001$ & 2.132 & 1.548 & 2.933 \\
\hline
\end{tabular}

DM, diabetes mellitus; NIDDM, non-insulin-dependent diabetes mellitus; IDDM, insulin-dependent diabetes mellitus; LOS, length of stay.

factor for failure to wean (OR 4.330; 95\% CI 1.215-15.436; $p=0.024)$ when compared to the non-DM group. Patients in the IDDM cohort had higher odds of reintubation (OR 4.219; 95\% CI 1.591-11.186; $p=0.004$ ), urinary tract infection (OR 1.454; 95\% CI 1.022-2.069; $p=$ 0.038 ), and prolonged hospital stay (OR 1.751; 95\% CI $1.360-2.255 ; p<0.001)$ compared to their non-DM counterparts. Additionally, patients with IDDM had higher odds of an extended length of hospital stay (OR 2.132; 95\% CI $1.548-2.933 ; p<0.001)$ when compared to the NIDDM cohort (Table 5).

\section{Discussion and Conclusion}

Limited data are available regarding the implications of DM severity on postoperative outcomes following minimally invasive hysterectomy. This study identifies both NIDDM and IDDM as independent risk factors for several postoperative complications following laparoscopic hysterectomy. Patients with NIDDM had higher odds of failure to wean from a ventilator within $48 \mathrm{~h}$, when compared to nondiabetic patients and pa- tients with IDDM had higher odds of reintubation, prolonged hospital stay, and urinary tract infection when compared with patients without DM. Furthermore, insulin-dependent diabetics had higher odds of a prolonged hospital stay when compared to their non-insulin-dependent diabetic counterparts. Factors associated with DM that may contribute to these outcomes include a weakened immune system and impaired baseline function of the pulmonary, cardiovascular, and renal systems [11-14]. Our results are consistent with previously published data in the fields of otolaryngology and orthopedics, in that we showed an increased incidence of most postoperative complications in patients with DM when compared to nondiabetic patients. These complications included infectious, renal, and cardiovascular etiologies [6-10]. In particular, we showed significantly higher odds of diabetic patients experiencing pulmonary complications, including failure to wean from a ventilator and unplanned reintubation [15].

The American Diabetes Association recommends patients with DM should attain a preoperative hemoglobin $\mathrm{A} 1 \mathrm{c}(\mathrm{HbA} 1 \mathrm{c})$ of $<7 \%$ prior to elective procedures; how- 
ever, it is not entirely clear how this goal was determined, and this recommendation has not been verified in the ambulatory surgical population $[6,16]$. Multiple studies have evaluated the relationship between preoperative $\mathrm{HbA} 1 \mathrm{c}$ and postoperative outcome in patients with DM. A study by Yong et al. [17] determined each percentage increase in $\mathrm{HbAlc}$ in hospitalized patients undergoing multiple types of surgery was associated with increased major complications, intensive care unit admission, and hospital LOS.

A prospective cohort study performed by Iavazzo et al. [18] on gynecologic oncology patients undergoing major gynecologic surgery found women with diabetes experienced almost double the rate of infectious complications following surgery compared to patients without DM. Infectious complications were experienced by $16.9 \%$ of women with $\mathrm{HbA} 1 \mathrm{c}<6.0 \%, 22.7 \%$ of women with $\mathrm{HbA1c} 6.0-6.4 \%, 43.5 \%$ of women with $\mathrm{HbA} 1 \mathrm{c}$ $6.5-8 \%$, and $37.5 \%$ of women with $\mathrm{HbA} 1 \mathrm{c}>8 \%$ [18]. Women with elevated $\mathrm{HbAlc}$ also experienced higher rates of noninfectious complications following surgery [18].

The Yong et al. [17] and Iavazzo et al. [18] studies are contradicted by a systematic review comprised of 20 studies conducted by Rollins et al. [6] that determined there was no definite relationship between $\mathrm{HbAlc}$ and 30-day patient outcomes following multiple types of surgical procedures. Moreover, preoperative optimization of HbAlc did not lead to a reduction in postoperative complications, including stroke, venous thromboembolism, acute kidney injury, extended LOS, and readmission.

Although the existing body of literature regarding the effect of DM severity on postoperative complications is varied, the results of the current study suggest that diabetes severity determined by insulin dependence status significantly affects postoperative outcomes in patients undergoing laparoscopic hysterectomy, with patients with IDDM at greatest risk of experiencing 30-day postoperative complications. Gynecologic surgeons must be aware of the increased risk of complications associated with DM, especially IDDM, to better guide patients in their decision making. Further research is needed to elucidate appropriate pre- and postoperative practices that optimize patient outcomes. As previously noted, the benefit of target preoperative $\mathrm{HbA} 1 \mathrm{c}$ levels on postoperative outcomes in patients undergoing laparoscopic hysterectomy remains unclear. Beyond insulin therapy, there is a lack of guidance about specific diabetic treatment regimens to optimize patients before and after surgery. For example, peroxisome-proliferator-activated receptor agonists have been extensively studied in patients with DM and metabolic syndrome and have been shown to have anti-inflammatory properties, which may be of benefit in the perioperative period [19].

Limitations in this study are related to the retrospective nature and the inherent limitations of information extraction from large databases. For this study, diabetic disease severity was stratified based on insulin dependence. Although insulin dependence can be used as an indicator of diabetes severity, another important indicator is $\mathrm{HbAlc}$, as it provides information about overall diabetes control [7]. Preoperative HbA1c values are not included in the ACS-NSQIP database so they could not be evaluated in this analysis. Another limitation of the study is that we were unable to distinguish laparoscopic from robot-assisted laparoscopic cases due to the use of CPT codes to identify cases. Laparoscopic and robot-assisted laparoscopic hysterectomies currently have the same CPT codes.

\section{Conclusion}

The goal of our study was to determine the effect of DM and its severity on postoperative complications for patients undergoing laparoscopic hysterectomy for benign indications. We sampled 56,540 patients who underwent laparoscopic hysterectomy from 2007 through 2016 and determined that patients with DM were at higher risk of experiencing postoperative complications compared to patients without DM. In particular, NID$\mathrm{DM}$ was determined to be an independent risk factor for failure to wean from a ventilator within $48 \mathrm{~h}$ and IDDM was determined to be an independent risk factor for reintubation, extended length of hospital stay, and urinary tract infection. Despite the higher rate of complications amongst diabetic patients, the overall rate of complications for hysterectomy utilizing the laparoscopic approach was low in all 3 cohorts of patients. When surgery is necessary and a minimally invasive surgical approach is feasible, this option should be offered to diabetic patients. However, gynecologic surgeons should consider all alternatives and carefully counsel patients with DM about their increased risks of surgery.

\section{Acknowledgments}

We would like to thank The George Washington University School of Medicine and Health Sciences for supporting our research.
Impact of Diabetes on Complications

Following Laparoscopic Hysterectomy
Gynecol Obstet Invest 2019;84:583-590 DOI: 10.1159/000501034 


\section{Statement of Ethics}

The authors have no ethical conflicts to disclose.

\section{Disclosure Statement}

Dr. Gaby N. Moawad is a speaker for Intuitive Surgical, Inc., The remaining authors have no conflicts of interests to declare.

The ACS-NSQIP and the hospitals participating in the ACS NSQIP are the source of the data used herein; they have not verified and are not responsible for the statistical validity of the data analysis or the conclusions derived by the authors.

\section{Funding Sources}

No funding sources to declare.

\section{Author Contributions}

M.V.V. and P.T. conceived the original idea. A.G., C.W., N.S., and E.E.T. performed data analysis. K.E.C. wrote the manuscript with support from M.V.V., H.N.R., A.G., M.V.V. and G.N.M. supervised the project.

\section{References}

1 The American Congress of Obstetricians and Gynecologists. 2011 Women's health stats \& facts. 2011 (Retrieved: January 13, 2018) Available from: https://www.acog.org/-/media/NewsRoom/MediaKit.pdf.

2 Moore BJ, Steiner CA, Davis H, Stocks C, Barrett ML. Trends in hysterectomies and oophorectomies in hospital inpatient and ambulatory settings, 2005-2013. Statistical Brief No. 214. Rockville (MD): Agency for Healthcare Research and Quality; 2016.

3 Cohen SL, Vitonis AF, Einarsson JI. Updated hysterectomy surveillance and factors associated with minimally invasive hysterectomy. JSLS. 2014 Jul-Sep;18(3):pii:e2014.00096.

4 Holte T, Goderstad J, Lieng M, Busund B, Norderhaug I. Laparoscopic surgery for benign gynaecological disease [Internet]. NIPH Systematic Reviews: Executive Summaries. 2009.

5 NCD Risk Factor Collaboration (NCD-RisC). Worldwide trends in diabetes since 1980: a pooled analysis of 751 population-based studies with 4.4 million participants. Lancet. 2016 Apr;387(10027):1513-30.

6 Rollins KE, Varadhan KK, Dhatariya K, Lobo DN. Systematic review of the impact of $\mathrm{HbA1c}$ on outcomes following surgery in patients with diabetes mellitus. Clin Nutr. 2016 Apr;35(2):308-16.

7 Chuah L, Papamargaritis D, Pillai D, Krishnamoorthy A, le Roux C. Morbidity and mortality of diabetes with surgery. Nutr Hosp. 2013 Mar;28(Suppl 2):47-52.
8 Belmont PJ Jr, Davey S, Rensing N, Bader JO, Waterman BR, Orr JD. Patient-based and surgical risk factors for 30-day postoperative complications and mortality after ankle fracture fixation. J Orthop Trauma. 2015 Dec;29(12): e476-82.

9 Belmont PJ Jr, Goodman GP, Waterman BR, Bader JO, Schoenfeld AJ. Thirty-day postoperative complications and mortality following total knee arthroplasty: incidence and risk factors among a national sample of $15,321 \mathrm{pa}-$ tients. J Bone Joint Surg Am. 2014 Jan;96(1): 20-6.

10 Rosado P, Cheng HT, Wu CM, Wei FC. Influence of diabetes mellitus on postoperative complications and failure in head and neck free flap reconstruction: a systematic review and meta-analysis. Head Neck. 2015 Apr;37(4): 615-8.

11 Lauruschkat AH, Arnrich B, Albert AA, Walter JA, Amann B, Rosendahl UP, et al. Diabetes mellitus as a risk factor for pulmonary complications after coronary bypass surgery. J Thorac Cardiovasc Surg. 2008 May;135(5): 1047-53.

12 Filimonov A, Chung SY, Wong A, Brady JS, Baredes S, Eloy JA. Effect of diabetes mellitus on postoperative endoscopic sinus surgery outcomes. Int Forum Allergy Rhinol. 2017 Jun;7(6):584-90.

13 Jones RE, Russell RD, Huo MH. Wound healing in total joint replacement. Bone Joint J. 2013 Nov;95-B(11 Suppl A):144-7.
14 Hart A, Funderburk CD, Chu CK, PinellWhite X, Halgopian T, Manning-Geist B, et al. The impact of diabetes mellitus on wound healing in breast reconstruction. Ann Plast Surg. 2017 Mar;78(3):260-3.

15 Chung SY, Govindan A, Babu A, Tassler A. Thyroidectomy complications in patients with diabetes mellitus. Otolaryngol Head Neck Surg. 2019 Apr;194599819835793.

16 Joshi GP, Chung F, Vann MA, Ahmad S, Gan TJ, Goulson DT, et al.; Society for Ambulatory Anesthesia. Society for Ambulatory Anesthesia consensus statement on perioperative blood glucose management in diabetic patients undergoing ambulatory surgery. Anesth Analg. 2010 Dec;111(6):137887.

17 Yong PH, Weinberg L, Torkamani N, Churilov L, Robbins RJ, Ma R, et al. The presence of diabetes and higher HbAlc are independently associated with adverse outcomes after surgery. Diabetes Care. 2018 Jun;41(6) $1172-9$.

18 Iavazzo C, McComiskey M, Datta M, Ryan M, Kiernan J, Winter-Roach B, et al. Preoperative HBA1c and risk of postoperative complications in patients with gynaecological cancer. Arch Gynecol Obstet. 2016 Jul; 294(1):161-4.

19 Berger JP, Akiyama TE, Meinke PT. PPARs: therapeutic targets for metabolic disease. Trends Pharmacol Sci. 2005 May;26(5):24451. 